\title{
The digital transformation of entrepreneurial work
}

\author{
Vincenzo Corvello, Monica De Carolis and Saverino Verteramo \\ Department of Mechanical, Energy and Management Engineering, \\ University of Calabria, Rende, Italy, and \\ Annika Steiber \\ Menlo College, Atherton, California, USA
}

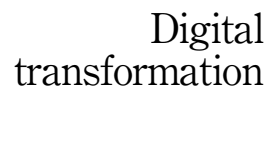

\begin{abstract}
Purpose - This paper explores digital transformation's impact on the work of owners in entrepreneurial firms. The interplay between working practices and technology is analyzed, taking into account the organizations' specific contexts.

Design/methodology/approach - A multiple case study design was applied. Eight cases of entrepreneurial firms, defined as companies that bring new products and services to the market by creating and seizing opportunities, were selected, with the goal to maximize the diversity of cases. The sample includes both smalland medium-sized firms, as well as high- tech and low- tech companies in equal number. Interviews have been used to collect both quantitative and qualitative data, which was analyzed in a structured way.

Findings - The digital transformation of entrepreneurial work, that is the daily work of entrepreneurs, is an evolutionary, practice-based phenomenon, rather than the result of rational design. The use of different digital tools is interrelated and depends on the characteristics, and dynamics of the surrounding environment.

Practical implications - The findings of this study are relevant to entrepreneurs interested in understanding the dynamics of their working practice, to software development firms interested in entrepreneurs as customers and to institutions interested in the education of entrepreneurs.

Originality/value - To the best of the authors' knowledge this is the first study which considers the interplay between digital technology and the daily activities of entrepreneurs, considered as a whole. It provides insights on how these interconnected dimensions evolve, thus contributing to understanding the work of entrepreneurs, and as a consequence the dynamics of entrepreneurial firms in the context of digital transformation of organizations.
\end{abstract}

Keywords Digital transformation, Entrepreneurs, Work organization, Small- and medium-sized enterprises, New technologies

Paper type Research paper

\section{Introduction}

Entrepreneurs play a central role in the creation, development and survival of firms (Donbesuur et al., 2020). In particular, entrepreneurial ventures are those organizations that, because of their young age or small size, are built around entrepreneurs (Piva, 2018). Entrepreneurial ventures are of great importance for all modern economies (Jayawarna et al., 2014). Understanding entrepreneurial daily activities is of crucial importance to support entrepreneurs, and thereby small- and medium-sized enterprises, that largely rely on the effectiveness of their owners (Donbesuur et al., 2020).

Academic research on entrepreneurship has devoted attention to the features that distinguish entrepreneurs with respect to other individuals (Presenza et al., 2020), as well as to

(C) Vincenzo Corvello, Monica De Carolis, Saverino Verteramo and Annika Steiber. Published by Emerald Publishing Limited. This article is published under the Creative Commons Attribution (CC BY 4.0) licence. Anyone may reproduce, distribute, translate and create derivative works of this article (for both commercial and non-commercial purposes), subject to full attribution to the original publication and authors. The full terms of this licence may be seen at http://creativecommons.org/licences/by/4.0/ legalcode.

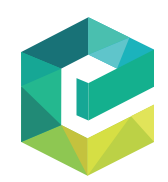

International Journal of Entrepreneurial Behavior \& Research
Vol. 28 No. 5, 2022 pp. 1167-1183 Emerald Publishing Limited 1355-2554 DOI 10.1108/IJEBR-01-2021-0067 
IJEBR 28,5

the characteristics of successful entrepreneurs (Watson et al., 2020; Donbesuur et al., 2020) and the context in which they operate (Ruiz-Palomino and Martínez-Cañas, 2021). Also, the behavior of entrepreneurs has been the object of interest of several scholars (e.g. Contin-Pilart et al., 2020). However, with few notable exceptions (e.g. Mueller et al., 2012; Johanisson, 2018), these studies focus on abstract capabilities (Kimmitt and Dimov, 2021) or individual behaviors (Artinger et al., 2015; Contin-Pilart et al., 2020), while the everyday work of entrepreneurs is seldom investigated.

As a result, academic understanding of the nature of entrepreneurs' daily work remains highly fragmented and thereby prevents the advancement of research on how specific behaviors can contribute to the launch and growth of new business ventures (Mueller et al., 2012).

This gap in the literature becomes even more relevant in a context of digital transformation, in which working practices undergo profound changes, included that of entrepreneurs (Scarmozzino et al., 2017). In the past few decades, people's lives and work have largely moved online. To understand how people work today, it is necessary to study their behavior and work practices in a digital context. Enabling technologies such as artificial intelligence, the Internet of Things (IoT) and big data, affect the phenomenon of new venture creation and the development of the launched venture (Oukil, 2011), but also the behavior of the individual entrepreneur (Andriole, 2017). This is obvious in the case of digital enterprises, but it also affects all other types of firms (Kraus et al., 2019; Nambisan, 2017). Consequently, in a context of digital transformation, it is important to understand how people work with Information and Communication Technology (ICT) tools.

The digital transformation of economic activities affects the work of entrepreneurs by providing tools that support their activity, but also as they change the very context in which entrepreneurs operate (Secundo et al., 2020). Entrepreneurs must adapt to the evolution of their context as the ICT disseminates and people become more familiar and proficient with digital technologies.

The coronavirus disease 2019 (COVID-19) pandemic, and the consequent lockdown have accelerated and amplified this phenomenon. The virtual work has become the main mode of interaction during the pandemic (Contreras et al., 2020). An indirect effect has been an increase of use of ICT tools by the population, as well as an increase in the digital competencies of individuals (Manco-Chavez et al., 2020).

Despite the fact that the impact of digital technologies has been largely investigated in other fields (Dominici et al., 2016), there is still a dearth of studies on how the work of entrepreneurs is changing, as a consequence of the digital transformation of the economy. These changes in working practices of entrepreneurs can be better understood by investigating how entrepreneurs use digital technologies in their daily activities. In other words, more research is needed on how entrepreneurs apply and use ICT tools in their daily work.

The purpose of this study is to understand how digital technologies impact on everyday working practices of entrepreneurs.

Therefore, this paper focuses on answering the two following research questions:

$R Q 1$. How do entrepreneurs use digital technologies in their everyday work?

$R Q 2$. How did the use of digital technologies by entrepreneurs evolve as a consequence of their diffusion?

In order to answer these questions, a qualitative research design was used. A multiple case study (Yin, 2014) involving eight cases of small- to medium-sized entrepreneurial firms was conducted. Data on, (1) the daily activities of entrepreneurs, (2) the role of digital technologies in the context of these activities and (3) the evolution of digital technologies' impact on 
entrepreneurs' daily activities over the past three years, were collected through interviews and documentary sources.

The results of this study are not only relevant for entrepreneurs but also for other categories of stakeholders interested in the phenomenon of entrepreneurial firms: scholars, universities and educational institutions, policymakers and ICT developers. Indeed, understanding the daily work of entrepreneurs will make it easier to support the activity of firm owners by developing more efficient technological tools, designing better training courses and materials, and developing public programs to support these activities. In turn, more effective entrepreneurs will facilitate the success of their firms for the benefit of the whole economy (Piva, 2018).

The paper is organized as follows: the section below describes the theoretical context and main findings from earlier literature on the entrepreneurial work and the role of ICT in this work. The following section discusses the methodology for the empirical study conducted in this study. The main results of the study are then presented and discussed. The paper ends with a discussion of results and how digital technologies have impacted the entrepreneurial work. Finally, conclusions, implications, limitations and future research are presented.

\section{Theoretical background}

\subsection{Role and activities of entrepreneurs}

The survival and success of entrepreneurial firms, defined as companies that bring new products and services to the market by creating and seizing opportunities, depends to a large extent on the work and capabilities of founders or owners (Cowling and Nadeem, 2020). Entrepreneurs are those individuals whose decisions determine to a large extent the strategy and organization of this kind of (usually small- to medium-sized) companies. Within these organizations, owners play different roles and are engaged in different kind of activities: directing, planning, monitoring, selling and coordinating (Mueller et al., 2012). The owners design the organization (Burton et al., 2019) and define its strategy (Cullen, 2019). The success of entrepreneurial firms has been linked to the entrepreneur's intellectual capital (Galabova, 2014), capabilities (Joshi and Srivastava (2015) and personal networks (Bagley, 2019). The past experience of the entrepreneur has been found to affect several aspects of a firm's performance like innovation (Deligianni et al., 2020), growth (Batjargal et al., 2019).

As a consequence, the behavior of entrepreneurs has been the object of several studies (Hinz, 2017).

However, most of these studies focus on abstract behaviors (e.g. planning, networking), rather than specific activities (Gartner et al., 2010). In their seminal study, Mueller and colleagues selected 12 entrepreneurs of nascent and mature entrepreneurial firms and observed their daily work. They singled out eight main categories of activities which constitute the basis of entrepreneurial work (Mueller et al., 2012). They found that start-up entrepreneurs spent significantly more time on the analytical and conceptual work, while growth entrepreneurs spent more time on business and organization, as well as communicating with others.

Being involved in so many different activities, each of great importance, entrepreneurs often have to face limited time availability. Entrepreneurs' time is a crucial resource for these ventures and the allocation of entrepreneurs' time influences the venture's performance (Piva, 2018).

Technology, in particular, has been found to affect the behavior of entrepreneurs and has an impact on its organization and outcomes (Shafigullina et al., 2020). Understanding the impact of technology on the entrepreneurial work is thereby of importance to better understand what new business owners actually do and how to support them. 
IJEBR

28,5

\subsection{Digital technologies and the transformation of entrepreneurial work}

The use of digital technology is not a new topic in management and organization studies. Media richness theory (Daft and Lengel, 1984) considered the use of technology as a rational choice, based on the correct association of the right communication medium with the task at hand. This approach has been challenged by successive theories which highlight the importance of the experience of the user, like channel expansion theory (Carlson and Zmud, 1999). More recent approaches have described the relation between technology and work as an evolutionary phenomenon, in which individuals, normally guided by a certain degree of inertia, experiment with new technologies as they become available and therefore more or less slowly modifying their working practices. Among these approaches are the media compensation theory (Hantula et al., 2011) and the practice-based approaches to the study of technology (Orlikowski, 2010).

The relation between technology and work can be observed starting also from internal factors, as the characteristics of individuals (Nambisan, 2017). Digital awareness, that is education, readiness and proneness to digital utilization, is expected to be an antecedent of the digital transformation of working practices (Li et al., 2018, Garzoniet al., 2020).

In this paper, the attention is focused on the role of external factors, particularly meaningful in this scenario, where pandemic dramatically accelerated the need to quickly change toward digitalization (Contreras et al., 2020; Manco-Chavez et al., 2020).

Digital technologies are transforming small and large organizations (Li et al., 2018). They are transforming the everyday work, as well as behavior and capabilities of individuals (Andriole, 2017 Anim-Yeboah et al., 2020). Every aspect of the organization of work is affected by this transformation (Lee, 2016; Neirotti et al., 2019).

For example, in their study of Uber, Rosenblat and Stark found that digital technologies profoundly modify the relation between employees' autonomy and employer's control, delegating control to algorithms and allowing for a higher degree of flexibility in employees behavior (Rosenblat and Stark, 2016).

Digital technologies are able to transform the way work is conducted both in intellectual professions (Salamon, 2020) and in more traditional settings, for example, increasing the speed and precision of execution (Trivelli et al., 2019).

ICT affects the spatial, as well as the temporal dimension of work, with the possibility to increase workers' satisfaction, while at the same time contributing to better satisfy the firm's operational needs (Neirotti et al., 2019).

The work of entrepreneurs is also affected by the diffusion of digital technologies (Shafigullina et al., 2020), both because these technologies are enablers of new ways of working (Rosenblat and Stark, 2016), and because of the change the context entrepreneurs work in (Kraus et al., 2019).

With reference to their role of enablers of digital transformation, it must be noted that digital technologies are the tools entrepreneurs use in their work. Entrepreneurs use mobile phones, emails, dashboards, as other workers use screwdrivers, hammers or drills. As a consequence, it is through digital tools that entrepreneurs make sense of their role and activities (Symon and Whiting, 2019).

Fernandez and colleagues studied micro-entrepreneurs in Rio de Janeiro, finding that digital technologies profoundly changed the timing of entrepreneurial work (Fernandes et al., 2019).

By giving access to collective intelligence, digital technologies modify the processes through which entrepreneurs interpret the surrounding environment, thus finding new opportunities and designing strategies (Dellermann et al., 2020).

Technologies like social networking websites have been found to facilitate learning and knowledge exchange among entrepreneurs (Scarmozzino et al., 2017). Digital platforms not only affect control but also collaboration, providing new modes for entrepreneurs to work 
together with employees, which increase democracy and enhancing trust (Kirsanova et al., 2021).

As found by Depaoli and colleagues, digital technologies can contribute by reducing the need for monitoring and control in entrepreneurial firms, allowing entrepreneurs to refocus on the relationship among business goals, organizational capabilities and communication requirements (Depaoli et al., 2020).

Therefore, digital technologies strongly impact on the daily work of people. However, few studies try to analyze in depth the impact on entrepreneurs' everyday activities. These technologies can have an impact at different levels: strategic and operational.

The pandemic has accelerated the digital transformation of organizations, providing an opportunity to study how these phenomena dynamically evolve and what are their main visible effects.

\section{Methodology}

\subsection{Research design and sample}

A multiple case study approach was chosen in order to analyze digital transformation's impact on the work of entrepreneurs in different contexts, which increases the validity and generalizability of the findings. This approach is especially useful to address "how" and "why" questions in a real-world context (Yin, 2014).

To increase the generalizability of results, cases can be selected strategically (Flyvbjerg, 2006) to reflect the maximum possible amount of variation. The participating organizations were identified via information from the media, the Internet and personal networking.

Table 1 summarizes the characteristics of the firms in the sample. Eight entrepreneurial firms were selected for the study. Four small and four medium-sized entrepreneurial firms were identified. To distinguish between small- and medium-sized firms, the parameters set by the European Union were used (EU recommendation, 2003/361). In order to control for sector of activity, four manufacturing and four service firms were selected. Attention has been paid to the fact that both low- and high-tech companies were represented in the sample.

Interviewees were the entrepreneurs, that is owners of the company, who also have the apical role in the management of the organization.

\subsection{Data collection}

Data for the different cases were collected between November and January 2020, with 16 interviews (two for each case) across the eight case organizations. The interviews lasted between 30 and $60 \mathrm{~min}$ and were conducted in conference calls, using a semi-structured questionnaire. For each organization the first interview had the goal of collecting the needed information while the second one was a follow-up interview with the goal of integrating and validating information. The interview partners were offered the questions prior to the interviews. Interviews were recorded and transcribed.

\begin{tabular}{lccllcc}
\hline Company & $\begin{array}{c}\text { Number of } \\
\text { Employees }\end{array}$ & Revenue & Sector & $\begin{array}{l}\text { High tech/ } \\
\text { Low tech }\end{array}$ & $\begin{array}{c}\text { Number of } \\
\text { interviews }\end{array}$ & $\begin{array}{c}\text { Total duration of } \\
\text { interviews }\end{array}$ \\
\hline A & 85 & $5 \mathrm{M}$ & Consultancy & High-tech & 2 & $1 \mathrm{~h} 30 \mathrm{~min}$ \\
$\mathrm{~B}$ & 79 & $10 \mathrm{M}$ & Printing & Low-tech & 2 & $1 \mathrm{~h} 30 \mathrm{~min}$ \\
$\mathrm{C}$ & 39 & $7 \mathrm{M}$ & Tinsmithery & Low-tech & 2 & $1 \mathrm{~h} 30 \mathrm{~min}$ \\
$\mathrm{D}$ & 16 & $1 \mathrm{M}$ & ICT & High-tech & 2 & $1 \mathrm{~h} 30 \mathrm{~min}$ \\
$\mathrm{E}$ & 9 & $200 \mathrm{~K}$ & ICT & High-tech & 2 & $1 \mathrm{~h} 30 \mathrm{~min}$ \\
$\mathrm{~F}$ & 8 & $1.2 \mathrm{M}$ & Agri-food & Low-tech & 2 & $1 \mathrm{~h} 30 \mathrm{~min}$ \\
$\mathrm{G}$ & 7 & $100 \mathrm{~K}$ & Furniture & Low-tech & 2 & $1 \mathrm{~h} 30 \mathrm{~min}$ \\
$\mathrm{H}$ & 4 & $150 \mathrm{~K}$ & Consultancy & High-tech & 2 & $1 \mathrm{~h} 30 \mathrm{~min}$
\end{tabular}

Table 1 .

Characteristics of the sample 
IJEBR 28,5

\section{2}

The questionnaire was composed of four parts: (1) general information about the company and the entrepreneur, (2) description of the everyday work (see Table 2), use of ICT tools (importance, frequency) and activities in which they are used (see Tables 3 and 4), (3) recent trends (more evident changes during the last three years in work practices for the entrepreneur, in the company and in the sector in which it operates), (4) any critical aspects on, e.g. difficulty of use, invasion of the privacy and so on.

During the interviews the entrepreneurs were asked if any category of activity, or relevant tools were missing from the proposed list. In case of an affirmative answer, the activities or tools were added to the list and information were gathered during the second round of (followup) interviews.

Considering that the same tools can be used on mobile devices or desktop computers, as well as taking into account the mobile nature of entrepreneurial work, interviewees were asked to distinguish between the use of each tool as a desktop or mobile application.

All interviews were recorded and transcribed, resulting in eight case reports. More specifically, as was mentioned above, two interviews per case were held: the first to collect data, the second to verify and validate the contents and results.

To supplement the interview data, additional information about the companies and their activities was collected in the form of documents from the interview subjects, as well as in the form of information available on the Internet.

\subsection{Data analysis}

The analysis was divided into two steps: first, within-case analyses were conducted to become more familiar with the individual cases. Second, cross-case analyses were conducted to integrate results of the eight cases and supplementary data.

\begin{tabular}{|c|c|c|}
\hline Activity & Definition & Examples \\
\hline $\begin{array}{l}\text { Exchanges } \\
\text { information and } \\
\text { opinion }\end{array}$ & $\begin{array}{l}\text { General exchange of information to keep } \\
\text { up to date, or inform others about current } \\
\text { tasks, issues, project status }\end{array}$ & $\begin{array}{l}\text { Reading incoming e-mails, sending e- } \\
\text { mails, talking about a customer } \\
\text { interaction with cofounder }\end{array}$ \\
\hline Directs & $\begin{array}{l}\text { Actions related to directing and giving } \\
\text { orders to employees }\end{array}$ & $\begin{array}{l}\text { Asking secretary to copy a certain } \\
\text { document, telling external service } \\
\text { provider what needs to be done, } \\
\text { delegating a task }\end{array}$ \\
\hline Consults and sells & $\begin{array}{l}\text { Actions related to consulting or selling to } \\
\text { (potential) customers, partners or } \\
\text { investors }\end{array}$ & $\begin{array}{l}\text { Calls a (potential) customer; sends an e- } \\
\text { mail to a potential customer }\end{array}$ \\
\hline $\begin{array}{l}\text { Works analytically } \\
\text { and conceptually }\end{array}$ & $\begin{array}{l}\text { Actions related to conceptual or } \\
\text { analytical work (alone or with others) and } \\
\text { actions related to the executing of a task }\end{array}$ & $\begin{array}{l}\text { Updating the business plan, writing an } \\
\text { offer, conducting Internet research, } \\
\text { writing a protocol, placing an order in the } \\
\text { system }\end{array}$ \\
\hline $\begin{array}{l}\text { Networks and } \\
\text { maintains } \\
\text { relationships }\end{array}$ & $\begin{array}{l}\text { Actions related to the development and } \\
\text { nurturing of relationships with } \\
\text { colleagues and business partners }\end{array}$ & $\begin{array}{l}\text { Having a coffee with employees, having } \\
\text { lunch with other entrepreneurs, } \\
\text { socializing via Facebook or Skype }\end{array}$ \\
\hline $\begin{array}{l}\text { Monitors and } \\
\text { controls }\end{array}$ & $\begin{array}{l}\text { Activities related to monitoring and } \\
\text { controlling work processes and results }\end{array}$ & $\begin{array}{l}\text { Asking employees about status of their } \\
\text { work, testing the functionality of the } \\
\text { company's website, checking prices in a } \\
\text { product catalog }\end{array}$ \\
\hline $\begin{array}{l}\text { Organizes and } \\
\text { coordinates }\end{array}$ & $\begin{array}{l}\text { Organization and coordination of } \\
\text { meetings, tasks and own work }\end{array}$ & $\begin{array}{l}\text { Updating to-do list, organizing folders and } \\
\text { documents; scheduling a meeting with } \\
\text { employees; printing a document; capacity } \\
\text { planning }\end{array}$ \\
\hline
\end{tabular}

Table 2.

Activities of the entrepreneur (Muller et al., 2012) 


\begin{tabular}{|c|c|c|c|c|c|c|c|c|c|c|c|}
\hline \multirow[b]{2}{*}{ Tool } & \multicolumn{2}{|c|}{ Average } & \multicolumn{2}{|c|}{ Av. High tech } & \multicolumn{2}{|c|}{ Av. low tech } & \multicolumn{2}{|c|}{$\begin{array}{l}\text { Av. Small } \\
\text { firms }\end{array}$} & \multicolumn{2}{|c|}{$\begin{array}{l}\text { Av. Medium- } \\
\text { sized firms }\end{array}$} & \multirow[t]{2}{*}{$\begin{array}{r}\text { Digital } \\
\text { transformation }\end{array}$} \\
\hline & Desk & Mobile & Desk & Mobile & Desk & Mobile & Desk & Mobile & Desk & Mobile & \\
\hline Voice calls & 1.25 & 4.2 & 1.5 & & 1 & 3.5 & 1 & 3.8 & 1.67 & 5 & \\
\hline Video calls & 3.75 & 1.12 & 3.75 & 1 & 3.75 & 1.25 & 3.4 & 1 & 4.33 & 1.33 & \\
\hline $\begin{array}{l}\text { Instant } \\
\text { messaging }\end{array}$ & 4.12 & 4.87 & 4.5 & 5 & 3.75 & 4.75 & 4.8 & 4.8 & 3 & 5 & 1173 \\
\hline Email & 4.5 & 2.5 & 5 & 3 & 4 & 2 & 4.5 & 2.5 & 3 & 2.5 & \\
\hline Social network & 3.12 & 3.12 & 3 & 3 & 3.25 & 3.25 & 2 & 2 & 5 & 5 & \\
\hline $\begin{array}{l}\text { Business } \\
\text { intelligence and } \\
\text { analytics }\end{array}$ & 1.5 & 1 & 2 & 1 & 1 & 1 & 1.4 & 1 & 1.67 & 1 & \\
\hline Dashboards & 3.25 & 1 & 3.25 & 1 & 3.25 & 1 & 2.8 & 1 & 4 & 1 & Table \\
\hline Databases & 2.25 & 1.37 & 3 & 1.75 & 1.5 & 1 & 2.4 & 1.6 & 2 & 1 & Frequency of use of \\
\hline $\begin{array}{l}\text { Project } \\
\text { management } \\
\text { systems }\end{array}$ & 1.87 & 1 & 2.25 & 1 & 1.5 & 1 & 1.6 & 1 & 2.33 & 1 & $\begin{array}{r}\text { digital tools } \\
(1=\text { seldom; } \\
5 \text { = very often })\end{array}$ \\
\hline
\end{tabular}

\begin{tabular}{|c|c|c|c|c|c|c|c|c|c|c|c|}
\hline \multirow[b]{2}{*}{ Tools } & \multicolumn{2}{|c|}{ Average } & \multicolumn{2}{|c|}{ Av. High tech } & \multicolumn{2}{|c|}{ Av. low tech } & \multicolumn{2}{|c|}{$\begin{array}{l}\text { Av. small } \\
\text { firms }\end{array}$} & \multicolumn{2}{|c|}{$\begin{array}{l}\text { Av. medium- } \\
\text { sized firms }\end{array}$} & \\
\hline & Desk & Mobile & Desk & Mobile & Desk & Mobile & Desk & Mobile & Desk & Mobile & \\
\hline Voice calls & 1.25 & 3.25 & 1.5 & 3 & 1 & 3.5 & 1 & 2.8 & 1.67 & 4 & \\
\hline Video calls & 4.375 & 1.5 & 4.25 & 1.5 & 4.5 & 1.5 & 4 & 1 & 5 & 2.33 & \\
\hline $\begin{array}{l}\text { Instant } \\
\text { messaging }\end{array}$ & 4 & 4 & 4.5 & 4.5 & 3.5 & 3.5 & 4.6 & 4.6 & 3 & 3 & \\
\hline Email & 3 & 2.5 & 3 & 3 & 3 & 2 & 3 & 2.5 & 3 & 2.5 & \\
\hline Social network & 2.75 & 2.75 & 2.5 & 2.5 & 3 & 3 & 2.2 & 2.2 & 3.67 & 3.67 & \\
\hline $\begin{array}{l}\text { Business } \\
\text { intelligence and } \\
\text { analytics }\end{array}$ & 1.5 & 1.25 & 2 & 1.5 & 1 & 1 & 1.4 & 1 & 1.67 & 1.67 & $\begin{array}{r}\text { Table } 4 . \\
\text { Variation in the } \\
\text { frequency of use of }\end{array}$ \\
\hline Dashboards & 3.12 & 1.25 & 3.25 & 1.5 & 3 & 1 & 2.8 & 1 & 3.67 & 1.67 & $\begin{array}{l}\text { It tools during the } \\
\text { last three years }\end{array}$ \\
\hline Databases & 2.37 & 1.62 & 3.25 & 2.25 & 1.5 & 1 & 2.4 & 1.6 & 2.33 & 1.67 & $(1=$ stayed the same or \\
\hline $\begin{array}{l}\text { Project } \\
\text { management } \\
\text { systems }\end{array}$ & 1.62 & 1.25 & 2.25 & 1.5 & 1 & 1 & 1.6 & 1 & 1.67 & 1.67 & $\begin{array}{r}\text { decreased; } \\
5=\text { increased } \\
\text { dramatically) }\end{array}$ \\
\hline
\end{tabular}

Interviews were coded with the goal of singling out relevant concepts and relations between concepts. Transcripts of the interviews were read and coded by at least two of the authors separately. The results were then confronted, and divergent interpretations were discussed until reaching consensus.

The interviews contained also question requiring the interviewed entrepreneur to express his/her perception with a number. Averages of the marks were calculated for the eight case studies and for each relevant subgroup in the sample (i.e. high-/low-tech firms and small-/ medium-sized firms). While the numbers express qualitative perceptions and, as a consequence, have no absolute value, they are useful to understand how entrepreneurs qualitatively perceive their work and the use of digital tools.

The results of the within- and cross-case analyses were used as a basis to detect similarities and differences between the cases. 
IJEBR

28,5

\section{4}

\section{Results}

In the next paragraphs, each case study is discussed individually. For each entrepreneur in the sample, the time allocated to each type of activity, the use of digital tools, the variation in their use and possible negative effects are discussed. In the following session, the eight cases are compared again with respect to activities, digital tools, variations in the use of tools and negative effects.

\subsection{Within-case analysis}

Case A is a medium-sized ICT consultancy company, developing information systems for customers in the apparel and creative industries. It works on a project-based fashion. The company grew rapidly in the past few years from less than 20 employees to over 80 , achieving a turnover of $5 \mathrm{~m}$ euro in 2019. The main activities the entrepreneur is involved in are networking and strategic analysis. During the interviews, he repeatedly stated that exploring new markets, looking for new technologies and evaluating the opportunities they create for the firm is what he perceives as his main tasks. Another activity which takes a lot of his time is selling, while less relevant tasks are the inward-oriented activities like directing and coordinating. The entrepreneur has a background in informatics and is proficient with information technology. The most frequently used tools are communication tools like phone and video calls. Also, social networking websites are used on a daily basis. During the last three years, the use of these digital tools has increased. In particular, desk video calls are the tool which showed the strongest increase in usage, even before the COVID-19 pandemic. One tool which is not used often, but is of strategic importance, is industry databases, which the entrepreneur uses when important decisions are made. Among the main problems caused by the use of digital tools the interviewee stated:

digital tools require a sequential approach. When I am in the same building as my employees and I am with a client, I can interrupt the meeting for a moment to ask for information or give directions to someone in another room. With virtual tools you cannot do the same. You cannot improvise. You have to schedule meeting in advance. This takes a lot of effort.

Case $\mathrm{B}$ is a medium-sized printing company that has been operating in the sector for 50 years. The owner is a second-generation entrepreneur. In interviews, he pointed out that networking is what occupies most of his time. His work has always forced him to frequently move, so he is familiar with digital media. In recent years, and even more during the pandemic, he has found it easier to interact with others given the greater familiarity that everyone has gained with these tools. The use of communication tools has increased during the last three years, as well as the use of dashboards and databases. During the interviews, he highlighted the ambiguity of digitally mediated communication, as well as the stress an individual undergoes because of being continuously reachable.

Case $\mathrm{C}$ is a medium-sized company specialized in metal processing. The sector in which it operates is a traditional one. The entrepreneur divides his time equally between customer relations and networking on the one hand, and management and monitoring of the business on the other. The interviewee stated that he is not very familiar with digital technologies. He makes extensive use of the simplest communication tools and of dashboards for corporate activity monitoring. The use of social networks for reaching potential customers and other partners has increased in the past three years, together with the use of video calls for remote meetings. As other entrepreneurs, also the interviewee in Case $\mathrm{C}$ stressed the negative effects of digital tools like ambiguity of communications, stress and interruptions.

Case D is a small software development company specialized in web applications for the tourism industry. Its customers are a limited number of large companies. In the past three years, it has doubled the number of employees and the turnaround. The owner perceives that 
networking and working analytically on the development of the business are his main activities. The collaborative climate of the organization makes directing and monitoring less time-consuming. During the interviews, the entrepreneur underlined the growing importance of both digital communication tools, dashboards and project management tools (which the company developed internally). The entrepreneur pointed out the strategic role of social networks.

not only the company website, but also personal profiles are a powerful tool for networking. Everyone spends a lot of time on Facebook. People know what you are doing and can instantly message you. There are huge opportunities for creating and maintaining relations with customers and partners.

Among the negative effects, he underlined the time-consuming nature of digital tools.

Case E is a small-sized ICT consultancy company, developing systems for monitoring patients in the medical sector. It is a relatively young company, which currently employs nine people and achieved a turnover of around 20,000 Euro in 2019. The founder is mainly absorbed by managerial and administrative activities. At a strategic level, he mainly works with pricing strategies and the budget. At an operational level, he mainly monitor internal activities and market opportunities. During the interview, the importance of collaboration tools was highlighted, which allowed full mobility and freedom of access from any point, in all phases of the life cycle of the activities and for all collaborators at the same time.

Smart working is essential in particular during the pandemic we are experiencing, as well as the dematerialization of content and independence from physical access points.

Among the risks, he mentioned the difficulty in keeping attention focused on priorities and the need to define shared ways of working, and archiving common documents.

Even if it would be enough to disconnect when you don't want to be disturbed, in reality you always feel the obligation to read and answer any call, message or email. Meetings are always more effective when live. If there is no "order" in the shared workspaces, it only generates confusion with the risk of slowing down or losing time or making mistakes.

Case $\mathrm{F}$ is a small company, operating in the agri-food sector for the national and international market. It currently employs eight people and achieved a turnover of around $1.2 \mathrm{~m}$ Euro in 2019. It is a family business. Ownership and management are shared between two brothers. The interviewee spends most of his time on managing the most important clients (large-scale retailers) as quality control and punctuality of deliveries in these cases are considered essential, so the owner prefers not to delegate. The remaining time he identify market opportunities, especially through participation in international trade fairs, in order to come into contact with those clients who are attentive to a niche product. The most used ICT tools are communication tools to manage relations with customers, in particular to monitor satisfaction ("sometimes a phone call is enough"). The entrepreneur is currently engaged in developing strategy to exploit social networks. Another crucial area for future developments based on digital technologies is to monitor production activities.

Case $\mathrm{G}$ is a small company operating in the furniture sector. It provides customized solutions for interior design, based mainly on woodworking. The main activities carried out by the interviewed entrepreneur are on one hand accounting/administrative, and on the other hand, managing relations with banks, consultants, suppliers or customers. He is sporadically involved in production and commercial activities. Given the nature of his work, the most used tools are internal accounting software and e-mails. In recent years, however, the use of agile tools for communication with customers (for example, WhatsApp) and for sharing documents via the cloud (sharing of technical projects with customers or bill of materials with suppliers) has become increasingly important. 
IJEBR

28,5

1176

Although, I prefer direct meetings with, for example, suppliers and customers, the tools allowed me to communicate faster. Once I used almost exclusively e-mail, now I use more often video calls for meetings and cloud-based tools for sharing files.

ICT tools have facilitated greater visibility in the market, mainly through social networks. It has been possible to convey a greater amount of information more quickly, such as rendering of projects and photos of the furniture solutions proposed. Further advantages derive from the spread of online forms, not only for purchases and sales, but also for the management of finances, banking and insurance practices. All those things allow him to save time.

Online forms also have a negative, if not well designed, aspect. A huge amount of time can be lost if the system is slow, or if information is not saved correctly. In the face of the speed of insertion, then one collides with the slowness of the assistance service in the event of unclear or ambiguous requests.

Case $\mathrm{H}$ is a young consultancy company, which supports its clients in innovation and fundraising for research and development (R\&D) activities. The founder mainly carries out activities of commercial nature. He monitors daily the progress of research projects, managed on behalf of their clients. Time is dedicated to the study of the financial instruments identified by the employees (e.g. new guidelines on $R \& D$ public financing instruments and new calls). With regard to ICT tools, cloud-based document sharing systems allow to easily check and analyze the solutions proposed by employees. These systems are used as project management tools and have become essential for coordination, direction and monitoring activities.

\subsection{Cross-case analyses}

4.2.1 Activities. The interviewed entrepreneurs considered selling, networking and working analytically as their main responsibilities, while inward-oriented activities like monitoring and coordinating are less relevant (see Table 5). When comparing the subgroups of firms in our sample, the finding is that these three categories of activities take a larger part of the time of entrepreneurs in medium-sized firms, compared to small ones. In small firms, the division of work is more balanced between these three categories of activities, and more inwardoriented ones like monitoring or directing. Consistently, one of the interviewed entrepreneurs observed that:

as the business grows and the number of clients increases, I have to spend my time outside of [name of the company]. I need my employees to be more autonomous and fortunately they are.

There is not a significant difference in the time devoted to different activities when comparing high- and low-tech companies. However, the analysis of the interviews highlights how networking in low-tech enterprises is strongly linked to finding new customers, while in hightech organizations, it is also important for keeping up to date with advancements in technology, and for market intelligence purposes. As one of the interviewees stated:

Table 5.

Time devoted by the entrepreneurs to each category of activities $(1=$ less than $5 \%$; $5=$ over $30 \%$ of yearly working time)

\begin{tabular}{lccccc}
\hline Activity & Average & Av. high tech & Av. low tech & Medium & Small \\
\hline Exchanges information and opinion & 2.25 & 2.25 & 2.25 & 2 & 2.4 \\
Directs & 2.375 & 2.75 & 2 & 2 & 2.6 \\
Consults and sells & 3.25 & 3.25 & 3.25 & 3.67 & 3 \\
Works analytically and conceptually & 3.125 & 3.75 & 2.5 & 2.67 & 3.4 \\
Networks and maintains relationships & 3.125 & 3 & 3.25 & 4 & 2.6 \\
Monitors and controls & 2.625 & 2.75 & 2.5 & 2.67 & 2.6 \\
Organizes and coordinates & 2.625 & 2.5 & 2.75 & 2.67 & 2.6 \\
\hline
\end{tabular}


before the pandemic I was never in my office. I have to be present at the tables where the latest developments are discussed.

4.2.2 Use of digital tools. The relational nature of entrepreneurial work is underlined also by the results concerning the use of digital tools (see Table 4). Communication tools, like voice calls, video and instant messaging, are considered as both the most used and most important tools for the work. Confronting desktop and mobile applications, as could be expected, voice calls are used in mobile mode, while the use of desktop computers is more common for video calls. Instant messaging is equally diffused in desktop and mobile mode. Desktop computers are also more suitable in the case of tools for monitoring and control (e.g. project management systems) or business intelligence.

When comparing high- and low-tech companies, it appears that the use of digital tools is less frequent in low-tech organizations with the notable exception of dashboards and social networks. The analysis of the transcripts of the interviews suggests that dashboards are used often in low-tech organizations to monitor and control operations, which in the studied lowtech organizations involve high volumes, fragmented activities, associated with requirement of timeliness (for example, in the agri-food business). However, also the interviewees of hightech organizations specified that dashboards and business intelligence tools, even if used less often than communication tools, can be of great importance. It seems that the use of these tools in high-tech companies is more oriented on decision-making than monitoring operations. As one interviewee of a small high-tech company stated:

I need to know what is going on with the orders, but I do not have as much time as I had a few years ago. I need few, simple KPIs. We developed our own system internally.

Comparing small- and medium-sized companies, results show that entrepreneurs of small companies prefer voice over video calls. This appears to be consistent with the commercial nature of entrepreneurial work in small firms. In larger firms, entrepreneurs are more often involved in complex networking and analytical activities, organized in virtual meetings. As expected, the use of dashboards is more frequent in medium-sized firms than in smaller ones.

4.2.3 Evolution in the use of digital tools. In the first version of the questionnaire, entrepreneurs were asked if the use of digital tools had increased or decreased in the last three years. After the first round of interviews, it became apparent that the use of digital tools has increased during the last three years (only seldom remaining unvaried in the perception of the interviewees) for all the considered tools, both in the desktop and mobile mode (see Table 4). As a consequence, the questionnaire was modified. These results might be influenced by the lockdown following the COVID-19 pandemic, but the interviewees all agreed about the fact that this trend was already in place before the spread of the disease.

According to the interviewees for example, the use of video calls had dramatically increased before the lockdown. The same holds for instant messaging. The use of digital tools has increased slightly more in high-tech companies. More than one entrepreneur in high-tech companies underlined that being proficient with these tools, as well as the fact that employees and customers are also familiar with them, makes it natural to organize work activities in a virtual mode. As one of the interviewees stated:

I used to travel a lot [before the pandemics] and it was natural to arrange online meetings with the customer, or with my employees.

The use of instant messaging has increased more in small firms, while-medium sized firms have increased the use of dashboards.

4.2.4 Negative effects of digital tools. Several interviewees pointed out a negative side of digital tools. Among the most cited problems there is an increase in stress, also due to the difficulty of separating private from working life. Being continuously reachable also causes 
IJEBR 28,5

interruptions in work. Information overflow has been seen as a cause of loss of control. Interviewees feel that communication tools, databases, social networks have dramatically increased the available information. However, this is also true for customers and other partners. As a consequence, a higher pressure is put on the organization to comply with quality requirements. Dashboards and project management systems become of great importance.

Also, the ambiguity of communications has been addressed as a problem when interactions are mostly digitally mediated.

One interesting observation made by two interviewees is that digital interaction is somehow intrinsically sequential. As one of them stated:

When I am at the company's premises, I can interrupt a meeting in progress and verify information or ask an employee a question to find out the status of a project. Working online, these unscheduled conversations are difficult. This greatly increases the planning work required.

\section{Discussion}

Building on the work of Mueller and colleagues, the daily activities of entrepreneurs have been investigated (Mueller et al., 2012). Consistently with the results obtained by previous literature, it has been found that entrepreneurs need to balance an ample and diverse set of activities, and all the activities require time and attention (Reynolds and Curtin, 2010; Piva, 2018). Their perception, however, is that outward-oriented activities are their main responsibility. These activities include maintaining relations with customers and networking with relevant partners.

Consistently, the most frequently used tools are communication tools. Their use has dramatically increased during the last three years in all the studied organizations. Even if this trend has been accelerated by the lockdown following the COVID-19 pandemic, this trend was in place before. Also, databases and business intelligence tools support the ability of entrepreneurs to deal with the external environment. As a consequence, their use has increased as well.

To understand how contingent variables like the size of the firm, or its core technology impact the use of digital tools by entrepreneurs, the studied organizations have been selected in order to have representative subgroups of small versus medium organizations (Yin, 2014).

With reference to the impact of size, it emerged that the work of entrepreneurs in small firms is more of a commercial nature, while in medium-sized organizations the importance of networking with other partners and analytical work, in particular aimed at developing strategies and market/technology intelligence, increase.

Comparing entrepreneurs in high-tech versus low-tech organizations, it appears evident that the use of digital tools is more common and has grown more rapidly in recent years as a consequence of both the familiarity with technology among these entrepreneurs, but also because of the diffusion of digital tools among employees and customers.

It was interesting to note that the use of one tool is linked to the use of the others. Entrepreneurs perceive the digital dimension as a work milieu and not as a toolbox with mutually exclusive options. For example, when the use of communication tools increases and as a consequence, the available amount of information increases, also the use of tools like dashboards, augments.

These findings seem to be consistent with previous research on ICT tools, and in particular with channel expansion theory (Carlson and Zmud, 1999) and with media compensation theory (Hantula et al., 2011), as well as with research on the recursive interaction between people and technology (Orlikowski, 2010). 
Indeed, the experience of users, entrepreneurs in this case, seems to be guiding their behavior when using digital tools. Entrepreneurs in low-tech companies find lean tools more adequate than richer media like videoconferencing. The intrinsic richness of the medium (Daft and Lengel, 1984) is not sufficient to justify its use.

On the contrary, richer media can introduce ambiguity in communications (Sawyer, 2019). This observation can explain why an increase in the availability of information (due to an increase in the use of communication tools or social networks) is associated with frustration on one hand, and with an increase in the use of dashboards and business intelligence systems on the other hand, that is, with technology able to simplify information.

The diffusion of digital tools in the society is creating a milieu which requires an evolution in the way entrepreneurs carry out their work. Consistently with the literature on media compensation (Hantula et al., 2011), the findings of this study suggest that entrepreneurs tend to adopt the simplest behavior compatible with their goals, like using instant messaging for entrepreneurs in small firms, and, compatibly with their abilities, move to more complex tools as their environment requires them to do so, like the entrepreneurs in the high-tech companies in our sample. However, the choice is not rational, but it is the result of an evolutionary process, involving experimentation with new technologies as the environment makes them available, and consequent modification of working practices (Orlikowski, 2010).

Also, the acceleration in the use of digital tools consequent to the COVID-19 pandemic (Contreras et al., 2020; Manco-Chavez et al., 2020) can be easily framed in this approach. The situation of a lockdown has made more digital tools available, both to entrepreneurs and to their interlocutors, thus multiply the opportunities for experimentation and for the evolution of work practices.

\section{Conclusions}

Based on an extensive review of the literature, this is the first study to investigate the impact of digital transformation, and in particular of specific digital tools, on the work of entrepreneurs (Scarmozzino et al., 2017) and how it has evolved during the last years, particularly during the pandemic. Thereby, it provides important advancements for the literature on entrepreneurship and entrepreneurial firms.

This research advances knowledge by showing how the daily activities of entrepreneurs interplay with digital technology, causing an evolution of their work, guided by the specific context they work in (e.g. small- versus medium-sized organizations, high-tech versus lowtech companies, a dynamic environment).

\subsection{Practical implications}

While the importance of entrepreneurs' role is widely acknowledged, their daily work is little studied and understood (Mueller et al., 2012). The direct consequence is that entrepreneurs are not adequately supported through, for example, the development of specific ICT tools, or educational resources dedicated to them.

This study has practical implication for several categories of stakeholder. First, the entrepreneurs can have a clearer, analytical picture of the work of their colleagues and of the contribution digital tools can provide in their daily work; Second, software development companies interested in providing digital tools specifically designed for entrepreneurs will find this study insightful. Third, the same holds for educational institutions interested in understanding, and offering courses, relevant for business owners of entrepreneurial firms.

It is necessary to understand that the use of technology is an evolutionary and practicebased phenomenon, rather than the result of rational choices (Piercy and Carr, 2020). Digital tools need to be designed for an incremental adoption. Besides they must be flexible so that 
IJEBR 28,5

each entrepreneur can adapt their use to his specific abilities and to the evolving requirements of the environment. Tools offering unneeded possibilities are not only useless, but they can become a problem for the entrepreneur, who might risk to be overwhelmed by ambiguous information (Matthes et al., 2020).

Finally, the work in a digital environment requires a different organization of activities. More planning is needed, because in the absence of physical proximity, improvisation and casual interactions are more difficult. Entrepreneurs need to be trained in this new reality, as well as in tools simplifying their planning activities.

\subsection{Limitations and future research}

This is an exploratory, qualitative study. Its main goal is to gain insights into the phenomenon of the transformation of entrepreneurial daily work due to the diffusion of digital technologies. While the sample was purposely chosen to maximize the variability, and thus the representativeness of the studied companies, the number of cases analyzed is still limited and, as a consequence, results must be generalized with caution. The studied organizations are all located in the south of Italy. While the structural characteristics of these organizations do not show evident particularities, the peripherality of the territory they are located in might have affected the results. Finally, the study is based on the perception of only one interviewee per organization. Future studies should consider a larger sample, covering different geographical origin of the cases and introduce objective measures.

The nature of the phenomenon, as it emerges from this study, involves multiple variables linked by reciprocal and dynamic relations. As a consequence, from a methodological point of view, qualitative, longitudinal studies are needed (Yin, 2014) to better understand how practice and technology mutually shape each other. These mutual relationships need to be analyzed in future works aiming at an in depth understanding of the phenomenon. Furthermore, contextual variables such as digital readiness, need to be taken into account. Not only external conditions can accelerate the digitalization of work but also the attitude and competences of entrepreneurs.

While studies focusing on specific tools and activities might be of interest, attention should be put on the interplay between tools and activities. Indeed, one of the major findings of our study is that entrepreneurs need to balance their effort between different activities and to achieve this goal, use multiple tools to compensate each separate tool's own limitations.

\section{References}

Andriole, S.J. (2017), "Five myths about digital transformation", MIT Sloan Management Review, Vol. 58 No. 3, pp. 13-18.

Anim-Yeboah, S., Boateng, R., Awuni Kolog, E., Owusu, A. and Bedi, I. (2020), "Digital entrepreneurship in business enterprises: a systematic review", Lecture Notes in Computer Science (Including Subseries Lecture Notes in Artificial Intelligence and Lecture Notes in Bioinformatics), 12066 LNCS, pp. 192-203.

Artinger, S., Vulkan, N. and Shem-Tov, Y. (2015), "Entrepreneurs' negotiation behavior", Small Business Economics, Vol. 44 No. 4, pp. 737-757.

Bagley, M.J.O. (2019), "Networks, geography and the survival of the firm", Journal of Evolutionary Economics, Vol. 29 No. 4, pp. 1173-1209.

Batjargal, B., Webb, J.W., Tsui, A., Arregle, J.-L., Hitt, M.A. and Miller, T. (2019), “The moderating influence of national culture on female and male entrepreneurs' social network size and new venture growth", Cross Cultural and Strategic Management, Vol. 26 No. 4, pp. 490-521.

Burton, M.D., Colombo, M.G., Rossi-Lamastra, C. and Wasserman, N. (2019), "The organizational design of entrepreneurial ventures”, Strategic Management Journal, Vol. 13 No. 3, pp. 243-255. 
Carlson, J.R. and Zmud, R.W. (1999), "Channel expansion theory and the experiential nature of media richness perceptions", Academy of Management Journal, Vol. 42 No. 2, pp. 153-170.

Contin-Pilart, I., Larraza-Kintana, M. and Martin-Sanchez, V. (2020), "Entrepreneurs' planning behavior and new firm performance", Management Research, Vol. 18 No. 3, pp. 307-334.

Contreras, F., Baykal, E. and Abid, G. (2020), "E-leadership and teleworking in times of COVID-19 and beyond: what we know and where do we go", Frontiers in Psychology, Vol. 11, 590271, in press.

Cowling, M. and Nadeem, S.P. (2020), "Entrepreneurial firms: with whom do they compete, and where?", Review of Industrial Organization, Vol. 57 No. 3, pp. 559-577.

Cullen, U. (2019), "Sociocultural factors as determinants of female entrepreneurs' business strategies", Journal of Entrepreneurship in Emerging Economies, Vol. 12 No. 1, pp. 144-167.

Daft, R.L. and Lengel, R.H. (1984), "Information richness: a new approach to managerial behavior and organizational design", in Cummings, L.L. and Staw, B.M. (Eds), Research in Organizational Behavior, JAI Press, Homewood, IL, Vol. 6, pp. 191-233.

Deligianni, I., Sapouna, P., Voudouris, I. and Lioukas, S. (2020), "An effectual approach to innovation for new ventures: the role of entrepreneur's prior start-up experience”, Journal of Small Business Management. doi: 10.1080/00472778.2019.1698432.

Dellermann, D., Lipusch, N., Ebel, P. and Leimeister, J.M. (2020), "The potential of collective intelligence and crowdsourcing for opportunity creation", International Journal of Entrepreneurial Venturing, Vol. 12 No. 2, pp. 183-207.

Depaoli, P., Za, S. and Scornavacca, E. (2020), "A model for digital development of an interaction-based approach”, Journal of Small Business and Enterprise Development, Vol. 27 No. 7, pp. 1049-1068.

Dominici, G., Roblek, V., Abbate, T. and Tani, M. (2016), "Click and drive: consumer attitude to product development: towards future transformations of the driving experiences", Business Process Management Journal, Vol. 22 No. 2, pp. 420-434.

Donbesuur, F., Boso, N. and Hultman, M. (2020), "The effect of entrepreneurial orientation on new venture performance: contingency roles of entrepreneurial actions", Journal of Business Research, Vol. 118, pp. 150-161.

Fernandes, J., Mason, K. and Chakrabarti, R. (2019), "Managing to make market agencements: the temporally bound elements of stigma in favelas", Journal of Business Research, Vol. 95, pp. 128-142.

Flyvbjerg, B. (2006), "Five misunderstandings about case-study research”, Qualitative Inquiry, Vol. 12, pp. 219-245.

Galabova, L.P. (2014), "Recognition and management of intangibles by Bulgarian entrepreneurial firms", Journal of Intellectual Capital, Vol. 15 No. 3, pp. 376-391.

Gartner, W.B., Carter, N.M. and Reynolds, P.D. (2010), "Entrepreneurial behavior: firm organizing processes", in Acs, Z. and Audretsch, D. (Eds), International Handbook Series on Entrepreneurship, Springer, New York, NY, Vol. 5, pp. 99-127.

Garzoni, A., De Turi, I., Secundo, G. and Del Vecchio, P. (2020), "Fostering digital transformation of SMEs: a four levels approach”, Management Decision, Vol. 58 No. 8, pp. 1543-1562.

Hantula, D.A., Kock, N., D’Arcy, J.P. and DeRosa, D.M. (2011), "Media compensation theory: a Darwinian perspective on adaptation to electronic communication and collaboration", in Saad, G. (Ed.), Evolutionary Psychology in the Business Sciences, Springer, Berlin, pp. 339-363.

Hinz, A. (2017), "Entrepreneurial behaviour revisited: linking self-efficacy with effectuation", International Journal of Business and Society, Vol. 18 No. S2, pp. 245-260.

Jayawarna, D., Jones, O., Lam, W. and Phua, S. (2014), "The performance of entrepreneurial ventures: examining the role of marketing practices", Journal of Small Business and Enterprise Development, Vol. 21 No. 4, pp. 565-587. 
IJEBR 28,5

Johannisson, B. (2018), "Disclosing everyday practices constituting social entrepreneuring - a case of necessity effectuation", Entrepreneurship and Regional Development, Vol. 30 Nos 3-4, pp. 390-406.

Joshi, M. and Srivastava, A. (2015), "Enhancing dynamic capability: a case of Microlit", Journal of Entrepreneurship in Emerging Economies, Vol. 7 No. 1, pp. 67-79.

Kimmitt, J. and Dimov, D. (2021), "The recursive interplay of capabilities and constraints amongst microfinance entrepreneurs", International Journal of Entrepreneurial Behaviour and Research, Vol. 27 No. 3, pp. 600-628.

Kraus, S., Palmer, C., Kailer, N., Kallinger, F. and Spitzer, J. (2019), "Digital entrepreneurship", International Journal of Entrepreneurial Behavior and Research, Vol. 25 No. 2, pp. 353-375.

Kirsanova, E.V., Mokhirev, A.I., Sokolov, A.M., Suvorova, E.V. and Zikirova, S.S. (2021), "Platform cooperativism - a new model in the knowledge economy", Studies in Systems, Decision and Control, Vol. 316, pp. 141-147.

Lee, J. (2016), "Impact of ICT on work: introduction”, in Lee, J. (Ed.), The Impact of ICT on Work, Springer, Singapore, pp. 1-6.

Li, L., Su, F., Zhang, W. and Mao, J.Y. (2018), "Digital transformation by SME entrepreneurs: a capability perspective”, Information Systems Journal, Vol. 28 No. 6, pp. 1129-1157.

Manco-Chavez, J.A., Uribe-Hernandez, Y.C., Buendia-Aparcana, R., Vertiz-Osores, J.J., Alcoser, S.D.I. and Rengifo-Lozano, R.A. (2020), "Integration of icts and digital skills in times of the pandemic COVID-19", International Journal of Higher Education, Vol. 9 No. 9, pp. 11-20.

Matthes, J., Karsay, K., Schmuck, D. and Stevic, A. (2020), "Too much to handle': impact of mobile social networking sites on information overload, depressive symptoms, and well-being", Computers in Human Behavior, Vol. 105, 106217.

Mueller, S., Volery, T. and von Siemens, B. (2012), "What do entrepreneurs actually do? An observational study of entrepreneurs' everyday behavior in the start-up and growth stages", Entrepreneurship: Theory and Practice, Vol. 36 No. 5, pp. 995-1017.

Nambisan, S. (2017), "Digital entrepreneurship: toward a digital technology perspective of entrepreneurship", Entrepreneurship: Theory and Practice, Vol. 41 No. 6, pp. 1029-1055.

Neirotti, P., Raguseo, E. and Gastaldi, L. (2019), "Designing flexible work practices for job satisfaction: the relation between job characteristics and work disaggregation in different types of work arrangements", New Technology, Work and Employment, Vol. 34 No. 2, pp. 116-138.

Orlikowski, W.J. (2010), "The sociomateriality of organizational life: considering technology in management research", Cambridge Journal of Economics, Vol. 34 No. 1, pp. 125-141.

Oukil, M.S. (2011), "A development perspective oftechnology-based entrepreneurship in the Middle East and North Africa", Annals of Innovation and Entrepreneurship, Vol. 2 No. 1, pp. 1-13.

Piercy, C.W. and Carr, C.T. (2020), "The structuration of identification on organizational members' social media”, International Journal of Business Communication. doi: 10.1177/ 2329488420955215.

Piva, E. (2018), "Time allocation behaviours of entrepreneurs: the impact of individual entrepreneurial orientation", Economia e Politica Industriale, Vol. 45 No. 4, pp. 493-518.

Presenza, A., Abbate, T., Meleddu, M. and Sheehan, L. (2020), "Start-up entrepreneurs' personality traits. An exploratory analysis of the Italian tourism industry", Current Issues in Tourism, Vol. 23 No. 17, pp. 2146-2164.

Reynolds, P. and Curtin, R. (2010), New Business Creation: An International Overview, Springer, New York, NY.

Rosenblat, A. and Stark, L. (2016), "Algorithmic labor and information asymmetries: a case study of Uber's drivers", International Journal of Communication, Vol. 10, pp. 3758-3784. 
Ruiz-Palomino, P. and Martínez-Cañas, R. (2021), "From opportunity recognition to the start-up phase: the moderating role of family and friends-based entrepreneurial social networks", The International Entrepreneurship and Management Journal. doi: 10.1007/s11365-020-00734-2.

Salamon, E. (2020), "Digitizing freelance media labor: a class of workers negotiates entrepreneurialism and activism", New Media and Society, Vol. 22 No. 1, pp. 105-122.

Sawyer, R.K. (2019), "The role of failure in learning how to create in art and design", Thinking Skills and Creativity, Vol. 33, 100527.

Scarmozzino, E., Corvello, V. and Grimaldi, M. (2017), "Entrepreneurial learning through online social networking in high-tech startups", International Journal of Entrepreneurial Behavior and Research, Vol. 23 No. 3, pp. 406-425.

Secundo, G., Rippa, P. and Meoli, M. (2020), "Digital transformation in entrepreneurship education centres: preliminary evidence from the Italian Contamination Labs network", International Journal of Entrepreneurial Behaviour and Research, Vol. 26 No. 7, pp. 1589-1605.

Shafigullina, A.V., Akhmetshin, R.M., Martynova, O.V., Vorontsova, L.V. and Sergienko, E.S. (2020), "Analysis of entrepreneurial activity and digital technologies in business", Advances in Intelligent Systems and Computing, Vol. 908, pp. 183-188.

Symon, G. and Whiting, R. (2019), “The sociomaterial negotiation of social entrepreneurs' meaningful work", Journal of Management Studies, Vol. 56 No. 3, pp. 655-684.

Trivelli, L., Apicella, A., Chiarello, F., Rana, R., Fantoni, G. and Tarabella, A. (2019), "From precision agriculture to Industry 4.0: unveiling technological connections in the agrifood sector", British Food Journal, Vol. 121 No. 8, pp. 1730-1743.

Watson, A., Dada, O., López-Fernández, B. and Perrigot, R. (2020), "The influence of entrepreneurial personality on franchisee performance: a cross-cultural analysis", International Small Business Journal: Researching Entrepreneurship, Vol. 38 No. 7, pp. 605-628.

Yin, R.K. (2014), Case Study Research and Applications: Design and Methods, Sage, Los Angeles.

\section{Corresponding author}

Vincenzo Corvello can be contacted at: vincenzo.corvello@unical.it

For instructions on how to order reprints of this article, please visit our website:

www.emeraldgrouppublishing.com/licensing/reprints.htm

Or contact us for further details: permissions@emeraldinsight.com 